\title{
Ventilation and air distribution systems in buildings
}

\author{
Hazim Bashir Awbi * \\ School of Construction Management and Engineering, University of Reading, Reading, UK
}

Keywords: ventilation, room air distribution, performance of air distribution systems, ventilation systems, indoor air quality

\section{Introduction}

The need of building occupants for ventilation has been recognized many centuries ago; however, since the early 1970s, ventilation systems for buildings and transport systems have considerably evolved. This was invigorated by researchers who demonstrated the requirements for buildings to provide comfort and good air quality indoors (e.g., Fanger, 1972; Fanger and Christensen, 1986; Fanger, 1988; European Collaborative Action, 1992). Later on, this need evolved to address the additional energy requirement for buildings to achieve the indoor environment quality levels stipulated by those previous researchers (Awbi, 2003, 2007; Karimipanah et al., 2007, 2008).

Energy consumption for heating, cooling, and ventilating buildings often accounts for the largest part of a country's energy usage, which is still mainly based on fossil fuels. There is a great global emphasis on reducing the reliance of buildings on fossil fuel energy and a move toward Nearly Zero Carbon Buildings (NZCB). This requires a major shift in the way buildings and their integrated heating, cooling, and ventilation systems are designed, operated, and maintained. Achieving this goal will require a rethink of the traditional designs of and types of systems currently in use. The proportion of ventilation energy in comparison with the total energy use in a building is expected to increase as the building fabric energy performance improves and ventilation standards recommend higher ventilation rates for improving indoor air quality (IAQ). At the same time, new building regulations (Directive 2010/31/EC, 2010; Building Regulation, 2010) are imposing air-tight construction, which will inevitably impact on IAQ, health (e.g., sick building syndrome), and human productivity in some future buildings (Seppänen, 2012).

Despite recent advances in building ventilation (Nielsen, 1993; Etheridge and Sandberg, 1996; Skistad et al., 2004; Awbi, 2011; Müller et al., 2013), it is evident that complaints about poor IAQ have increased in recent years (Gunnarsen and Fanger, 1992; Fisk, 2000, Bakó-Biró, 2004; Fanger, 2006; Boestra and van Dijken, 2010). There is a need therefore for assessing current methods of building ventilation and developing ventilation systems that are capable of providing good IAQ and energy performance to satisfy building occupants and meet new building energy codes.

This article gives a brief overview of the various types of mechanical ventilation and air distribution systems that are used for buildings; highlighting those systems that are capable of providing better IAQ and energy efficiency. The aim is to provide some insight to those building professionals whose tasks are selecting ventilation systems for low energy buildings that can provide the necessary levels of IAQ for the occupants; and for the research community to continue research in this area in order to develop new ventilation concepts and deliver the desired performance.

\section{Status of Mechanical Ventilation and Air Distribution Systems}

Awbi HB (2015) Ventilation and air distribution systems in buildings.

Front. Mech. Eng. 1:4.

doi: 10.3389/fmech.2015.00004

Ventilation is the process of replacing contaminated indoor air with fresh air from outside the building. This can be fortuitous in the form of air leakage through cracks and openings in the building 
TABLE 1 | A summary of room air distribution types

\begin{tabular}{ll}
\hline Type $\quad$ Locations of air inlet and outlet \\
\hline
\end{tabular}

Mixing ventilation (wall supply and extract)

Mixing ventilation (ceiling supply and extract)

Displacement ventilation (wall supply and extract)

Impinging jet ventilation (ceiling supply and extract)

Confluent jets ventilation (wall supply and ceiling extract)

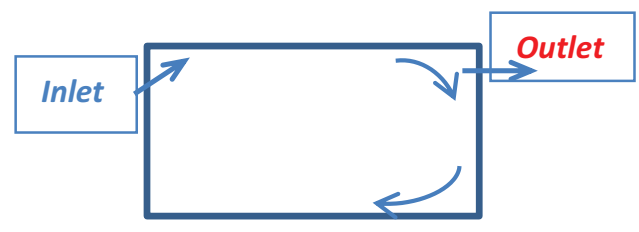

Main characteristics

- High momentum flow

- Uniform mixing through the room

- Can be used for cooling and heating

- Limited IAQ and energy efficiency

- High momentum flow

- Uniform mixing through the room

- Can be used for cooling and heating

- Suitable for large spaces

- Limited ventilation and energy effectiveness

- Buoyancy-driven stratified flow

- Limited flow penetration

- Only suitable for cooling

- High ventilation effectiveness

- Medium momentum flow

- Deep airflow penetration

- Can be used for cooling and heating

- High IAQ and energy efficiency envelop (air infiltration) or purposely provided ventilation in the form of natural, mechanical, or a combination of the two (hybrid or mixed-mode). In mechanical ventilation, the airflow is distributed by means of fans and ductwork arrangement throughout the building and then distributed in the room via air terminal devices or diffusers. The focus of this article is on the current status of mechanical room air distribution systems with a particular emphasis on recently developed methods of air distribution.

Various methods of mechanical ventilation and room air distribution have been implemented and used in different types of buildings over many years now. Some of these classical methods are still widely used, such as mixing ventilation (MV), but new concepts are currently being developed for wider commercialization, such as the impinging jets (IJ) and the confluent jets (CJ) systems. In a standard design of the air distribution system, the building (or room) is often considered as an empty space with allowance made for internal heat sources and external heat gains/losses but no account is normally given to localized heat sources and thermal plumes arising from them. In many cases, thermal plumes can have a major impact on the air movement not only in the case of displacement ventilation (DV) (which are its driving force) but MV too (Cho and Awbi, 2007). In practice, a simplistic design approach for ventilation systems that does not consider thermal plumes for instant could often lead to inappropriate performance in terms of air quality provision and energy performance.

A brief summary of some of the different methods of room air distribution, both the conventional and less conventional, is 
given below. Such systems can be categorized into six main types depending on the method of air supply and extract from the room (room air distribution). Each method is characterized by the airflow pattern it produces in the room and the location of the air supply/exhaust devices. More detailed information on available mechanical systems can be found in Cao et al. (2014) but the focus here is on those systems that are widely used or have the possibility of wider applications in future.

Mixing ventilation has been in use longer than any of the known mechanical ventilation systems and it is well documented in various ventilation guides and standards (e.g., ASHRAE Handbook, 2011). The principle behind a MV system is to mix fresh air with contaminated room air to reduce the contaminant concentrations in a room. Here, an air jet is normally supplied at the upper parts of the room (ceiling or wall at high level) at a high velocity (typically $>2.0 \mathrm{~m} / \mathrm{s}$ ) to provide air jets circulation around the room peripherals. Some air supply methods that are based on MV are given in Table 1. Normally, the airflow rates are determined by the number of air changes for the room, which is determined by cooling and heating loads for that room. With a properly designed system, the resulting temperature and contaminant concentration in the occupied zone (up to $1.8 \mathrm{~m}$ height) should be quite uniform. Although this is a widely used air distribution system, it is known that it is not very efficient in terms of good air quality provision and energy performance (Karimipanah et al., 2008).

Unlike MV, DV system is based on the principle of displacing contaminated room air with fresh air supplied from outside. Cool air is normally supplied at low velocity (typically $<0.5 \mathrm{~m} / \mathrm{s}$ ) at or near the floor to create an upward air movement (thermal plumes), as it warms up by heat sources in the room (see Table 1). This flow pattern will normally create vertical gradients of air temperature and contaminant concentration. Airflow rates for this method are normally determined by the limitation in air supply temperature (typically $>17^{\circ} \mathrm{C}$ ) in order to avoid draught due to low air temperatures at floor level. However, due to the fact that the room air movement is primarily driven by buoyancy forces, this method can only be used for cooling. This air distribution method is usually more energy efficient than MV as it requires lower fan power and has higher ventilation effectiveness than mixing.

Although a DV system usually provides a more efficient method of air supply it suffers from two main drawbacks: (1) it cannot be used in the heating mode; (2) the fresh air supply has a limited penetration depth into the room. A so-called hybrid air supply system combines the characteristics of both MV and DV systems and is capable of overcoming the shortcomings of the DV system. Some hybrid air distribution systems have recently been developed, such as the IJ system and the CJ system (Karimipanah and Awbi, 2002; Chen et al., 2012, 2013a,b) (see Table 1).

The IJ system uses a duct or opening for supplying a jet of air down toward the floor so that it spreads over a large area of the floor (Karimipanah and Awbi, 2002). As a medium momentum supply device, IJ ventilation can combine the positive effects of both mixing and displacement systems. The jet it produces has a higher momentum than that for DV and it can therefore spread more evenly over the floor. As a result, the system can provide a clean air zone in the lower part of the occupied zone like DV but is capable of reaching further positions in the room than a DV system. In addition, it is possible to use an IJ system in the heating mode as well as the cooling mode. In CJ system, a number of jets issuing from closely spaced slots or circular apertures in the same flow directions merge together a short distance downstream to form a single jet normally close to a room surface such as a wall or floor. The combined jets are then directed toward the floor to create a similar effect to that from an IJ system, thus producing a greater horizontal spread over the floor than a displacement jet system (Cho et al., 2008; Janbakhsh et al., 2009; Ghahremanian and Moshfegh, 2014a,b). The characteristics of CJ are similar to the IJ in terms of being a higher momentum room air supply rather than a buoyancy-driven flow as it is in the case of a DV system.

Studies involving IJ and CJ systems have shown that these methods of room air supply are capable of providing considerably better air quality performance and at the same time require less energy than the MV system (Karimipanah et al., 2008). Although the performances of IJ and CJ systems are quite close when compared with DV system with cooling mode, the latter method has many shortcomings such as its limitation in reaching long distances from the air supply point, low cooling capacity $\left(<40 \mathrm{~W} / \mathrm{m}^{2}\right.$ of floor area), and it is not suitable for heating (Karimipanah and Awbi, 2002; Cho et al., 2008; Almesri et al., 2013). Both IJ and CJ do not normally have such limitations.

\section{Future Development in Ventilation and Air Distribution}

As mentioned earlier, room air distribution and ventilation techniques have greatly been improved in the last 40-50 years. However, this important field of HVAC, which has a direct impact on people's health and productivity, has the potential for greater development as some commonly used methods are not always suitable for delivering the IAQ demanded by the building occupants and at the same time meeting stricter energy performance guidelines. As increased awareness of the impact of ventilation on human health and productivity is expected to become more topical, it is anticipated that more advances in the delivery of fresh air to occupants will be foreseen to meet people's aspirations. It would be expected therefore that:

- the unconventional methods of room air distribution will become more commonly used;

- wider application of demand control ventilation (DCV), i.e., a direct link of fresh air supply to IAQ;

- more reliance on using simulation tools for visualizing room air movement, such as computational fluid dynamics (CFD), to improve our prediction of the performance of ventilation systems at the design stage;

- a move toward more energy efficient methods of room air distribution;

- improvement of the quality assurance and maintenance procedures for ventilation systems. 


\section{References}

Almesri, I., Awbi, H. B., Foda, E., and Siren, K. (2013). Air distribution index for assessing the thermal comfort and air quality in uniform and nonuniform thermal environments. Indoor Built. Environ. 22, 618-639. doi:10.1177/ $1420326 \mathrm{X} 12451186$

ASHRAE Handbook. (2011). HVAC Application. Atlanta, GA: ASHRAE.

Awbi, H. B. (2003). Ventilation of Buildings, 2nd Edn. London: Spon Press.

Awbi, H. B. (2007). Ventilation Systems: Design and Performance. London: Spon Press.

Awbi, H. B. (2011). "Energy efficient ventilation for retrofit buildings," in Proceedings of $48^{\text {th }}$ AiCARR International Conference Energy Performance of Existing Buildings (Baveno), 23-46.

Bakó-Biró, Z. S. (2004). Human Perception, SBS Symptoms and Performance of Office Work During Exposure to Air Polluted by Building Materials and Personal Computers. Ph.D. Thesis, International Centre for Indoor Environment and Energy, Technical University of Denmark.

Boestra, A., and van Dijken, F. (2010). Indoor environment and energy efficiency of schools. REHVA J. 47, 33-38.

Building Regulation. (2010). Part F1: Means of Ventilation. London: Department for Communities and Local Government.

Cao, G., Awbi, H., Yao, R., Fan, Y., Sirén, K., Kosonen, R., et al. (2014). A review of the performance of different ventilation and airflow distribution systems in buildings. Build. Environ. 73, 171-186. doi:10.1016/j.buildenv.2013. 12.009

Chen, H. J., Moshfegh, B., and Cehlin, M. (2012). Numerical investigation of the flow behavior of an isothermal impinging jet in a room. Build. Environ. 49, 154-166. doi:10.1016/j.buildenv.2011.09.027

Chen, H. J., Moshfegh, B., and Cehlin, M. (2013a). Investigation on the flow and thermal behavior of impinging jet ventilation systems in an office with different heat loads. Build. Environ. 59, 127-144. doi:10.1016/j.buildenv.2012.08.014

Chen, H. J., Moshfegh, B., and Cehlin, M. (2013b). Computational investigation on the factors influencing thermal comfort for impinging jet ventilation. Build. Environ. 66, 29-41. doi:10.1016/j.buildenv.2013.04.018

Cho, Y., and Awbi, H. B. (2007). A study of the effect of heat source location in a ventilated room using multiple regression analysis. Build. Environ. 42, 2072-2082. doi:10.1016/j.buildenv.2006.03.008

Cho, Y. J., Hazim, B., Awbi, H. B., and Karimipanah, T. (2008). Theoretical and experimental investigation of wall confluent jets ventilation and comparison with wall displacement ventilation. Build. Environ. 43, 1091-1100. doi:10.1016/ j.buildenv.2007.02.006

Directive 2010/31/EC. (2010). On the Energy Performance of Buildings (Recast). Available at: http://eur-lex.europa.eu/LexUriServ/LexUriServ.do?uri=OJ:L: 2010:153:0013:0035:EN:PDF

Etheridge, D., and Sandberg, M. (1996). Building Ventilation: Theory and Measurement. Chichester: Wiley.

European Collaborative Action. (1992). Guidelines for Ventilation Requirements in Buildings. Report No. 11, EUR 14449EN. Luxembourg: Commission of the European Communities.

Fanger, P. O. (1972). Thermal Comfort. New York, NY: McGraw-Hill.
Fanger, P. O. (1988). Introduction of the olf and the decipol units to quantify air pollution perceived by humans indoors and outdoors. Energy Build. 12, 1-6. doi:10.1016/0378-7788(88)90051-5

Fanger, P. O. (2006). What is IAQ? Indoor Air 16, 328-334. doi:10.1111/j.1600-0668. 2006.00437.x

Fanger, P. O., and Christensen, N. K. (1986). Perception of draught in ventilated spaces. Ergonomics 29, 215-235. doi:10.1080/00140138608968261

Fisk, W. J. (2000). Health and productivity gains from better indoor environment and their relationship with building energy efficiency. Annu. Rev. Energy Environ. 25, 537-566. doi:10.1146/annurev.energy.25.1.537

Ghahremanian, S., and Moshfegh, B. (2014a). A study on proximal region of low Reynolds confluent jets - part 1: evaluation of turbulence models in prediction of inlet boundary conditions. ASHRAE Trans. 120, 256-270.

Ghahremanian, S., and Moshfegh, B. (2014b). A study on proximal region of low Reynolds confluent jets - part 2: numerical prediction of the flow field. ASHRAE Trans. 120-pp, 271-285.

Gunnarsen, L., and Fanger, P. O. (1992). Adaptation to indoor air pollution. Environ. Int. 18, 43-47. doi:10.1016/0160-4120(92)90209-M

Janbakhsh, S., Moshfegh, B., and Ghahremanian, S. (2009). A newly designed supply diffuser for industrial premises. Int J Ventilation 9, 59-68.

Karimipanah, T., and Awbi, H. B. (2002). Theoretical and experimental investigation of impinging jet ventilation and comparison with wall displacement ventilation. Build. Environ. 37, 1329-1342. doi:10.1016/S0360-1323(01)00117-2

Karimipanah, T., Awbi, H. B., Sandberg, M., and Blomqvist, C. (2007). Investigation of air quality, comfort parameters and effectiveness for two floor-level air supply systems in classrooms. Build. Environ. 42, 647-655. doi:10.1016/j.buildenv.2005. 10.016

Karimipanah, T., Awbi, H. B., and Moshfegh, B. (2008). The air distribution index as an indicator for energy consumption and performance of ventilation systems. J. Hum. Environ. Syst. 11, 77-84. doi:10.1618/jhes.11.77

Müller, D., Kandzia, C., Kosonen, R., Melikov, A. K., and Nielsen, P. V. (2013). Mixing Ventilation: Guide on Mixing Air Distribution Design. Brussels: REHVA Guidebook 19.

Nielsen, P. V. (1993). Displacement Ventilation: Theory and Design. Denmark: Aalborg University.

Seppänen, O. (2012). Effect of EPBD on future ventilation systems. REHVA J. 2 34-38.

Skistad, H., Mundt, E., Nielsen, P. V., Hagström, K., and Railio, J. (2004). Displacement Ventilation in Non-Industrial Premises. Brussels: REHVA Guidebook 1.

Conflict of Interest Statement: The author declares that the research was conducted in the absence of any commercial or financial relationships that could be construed as a potential conflict of interest.

Copyright (C) 2015 Awbi. This is an open-access article distributed under the terms of the Creative Commons Attribution License (CC BY). The use, distribution or reproduction in other forums is permitted, provided the original author(s) or licensor are credited and that the original publication in this journal is cited, in accordance with accepted academic practice. No use, distribution or reproduction is permitted which does not comply with these terms. 